\title{
Vaping Induced Pathological Changes in the Lung-A Case Report Study
}

\author{
Rashmi R Bhuyan*, Kumkum Vadera, \\ Harbor-UCLA Medical Center, USA.
}

* Corresponding author: Rashmi R Bhuyan, Harbor-UCLA Medical Center

Received Date July 07, 2020; Accepted Date: July 31, 2020; Published Date: August $07,2020$.

Citation: Rashmi R Bhuyan, Vadera K, (2020) Vaping Induced Pathological Changes in the Lung-A Case Report Study. J Cancer Research and Cellular Therapeutics, 4(1): Doi: 10.31579/2640-1053/103

Copyright: () 2020. Rashmi R Bhuyan. This is an open-access article distributed under the terms of the Creative Commons Attribution License, which permits unrestricted use, distribution, and reproduction in any medium, provided the original author and source are credited.

\begin{abstract}
Vaping associated pulmonary injury (VAPI), a group of respiratory symptoms, sometimes accompanied by nonspecific symptoms like generalized fatigue, body ache, fever, nausea, diarrhea, vomiting and chills that has been previously categorized as a diagnosis of exclusion and best described as an exogenous lipoid pneumonia, or chemical pneumonitis. Here we describe the onset of an exogenous cause of lipoid pneumonia in an otherwise healthy patient using cannabis-containing products. We explore, similarities in the clinical case, identify common clinical features, characteristic radiologic findings along with cytological changes in the lungs.
\end{abstract}

Key Words: Vaping associated pulmonary injury (VAPI); body ache; fever; nausea; diarrhea

\section{Introduction}

The outbreak of severe and acute pulmonary disease associated with the use of cannabis extract-containing vape pens and nicotine e-cigarettes has grown to 2,711 reported cases according to the most up-to-date data retrieved from the Center for Disease Control and Prevention (CDC) website posted on January 20, 2020 [1]. 27 confirmed death cases have been reported due to severe and acute pulmonary disease associated with e-cigarettes in all 50 states, the District of Columbia, and two U.S. territories (Puerto Rico and the U.S. Virgin Islands) [1].

Although chemical exposure has been postulated as a definitive cause, the acute incidence of pulmonary disease has brought national attention to this epidemic (2) and warrants more studies of clinical course, radiological findings and unique pathological changes in the lungs that will help in immediate medical management for VAPI with appropriate support, as reported in the case below.

\section{Case report}

A 30 year old female with history of anxiety, depression and marijuana use presented in the ED with dyspnea and hypoxic respiratory failure with presumed etiology of inhalation of injury vs hypersensitivity pneumonia. CT chest showed diffuse bilateral ground-glass changes with differential diagnosis of multifocal pneumonia vs interstitial pneumonia (Fig. 2). Due to sustained hypoxia, bronchoscopy was performed on day eight day of admission in the pulmonary intensive care unit. Patient responded well to steroids with infectious work up negative. She was discharged on a short course of Bactrim and oral prednisone $40 \mathrm{mg}$. Prednisone was tapered and discontinued eventually, with cessation of vaping and smoking, patient made complete recovery in few weeks at home.
On arrival in the emergency department, the patient was tachypneic with a respiratory rate of 46 breaths per minutes and oxygen saturation 70 at ambient air, blood pressure was $127 / 65 \mathrm{mmHg}$, heart rate 98 per minute. Started on high flow nasal cannula with improvement of oxygen saturation to high 90s. Subsequently patient was admitted to medical intensive care unit on empirical antibiotic coverage, bronchodilator inhalers and BiPAP for breathing fatigue with an oxygen flow at 40 L/min.

Physical examination is remarkable for diaphoresis, tachypnea, labored breathing with accessory muscle use, diffuse inspiratory and expiratory wheezing in all lung fields bilaterally. Differential diagnosis initially in the emergency department made were interstitial pneumonia vs multifocal pneumonia; VAPI was considered after cytology finding of lipid-laden macrophages in the bronchoalveolar lavage by bronchoscopy procedure was observed. Bronchoscopy showed normal vocal cord, airways without secretions, lesions or obstructions, bronchoalveolar lavage in the right middle lobe and left lower lobe performed with good return of foamy fluid. Patient was then started on oral steroids $60 \mathrm{mgs}$ per day, after that patient was observed to have notable improvement, BiPAP was changed to high flow nasal cannula at $40 \mathrm{~L} / \mathrm{min}$. Patient showed gradual improvement, was transitioned to room air on day fifteen. Oral steroid was weaned to $40 \mathrm{mg}$ daily for 7 days, then to $30 \mathrm{mg}$ per day for another 7 days, then $20 \mathrm{mg}$ per day for next 7 days, eventually completely discontinued.

\section{Imaging findings}

\section{CXR:}




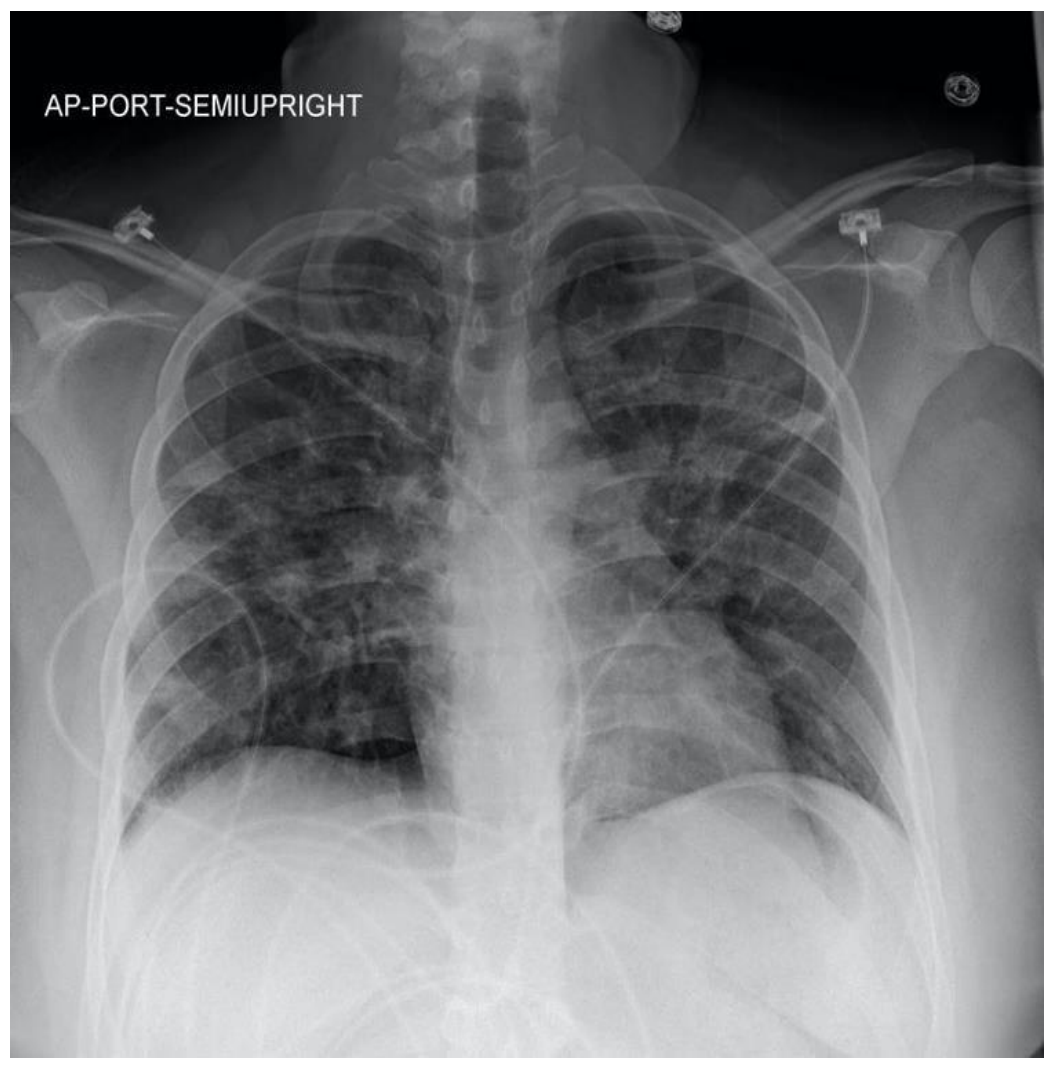

Figure. 1: Lungs are well expanded. Heart size is normal.

There is a hazy appearance to the interstitium bilaterally, worst in the perihilar distribution.

\section{CT Chest:}

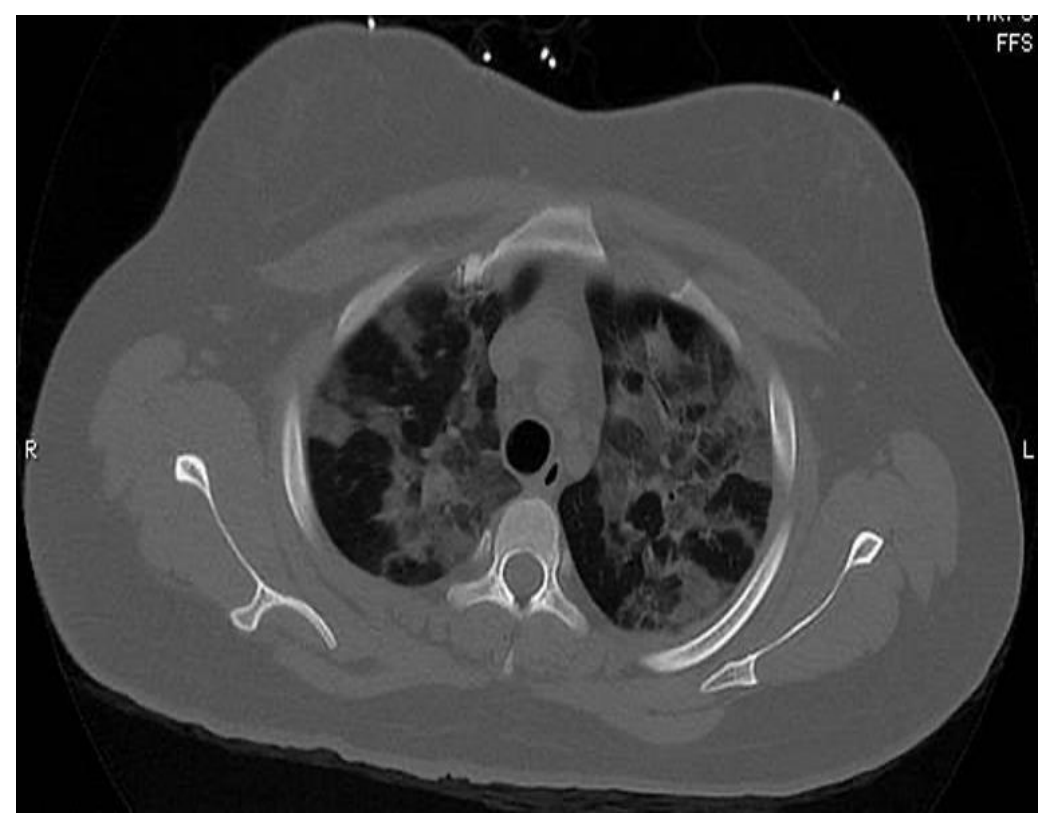

Figure. 2: Markedly increased bilateral, diffuse patchy ground-glass opacities which are upper and mid lung zone predominant.

\section{Histology Findings:}




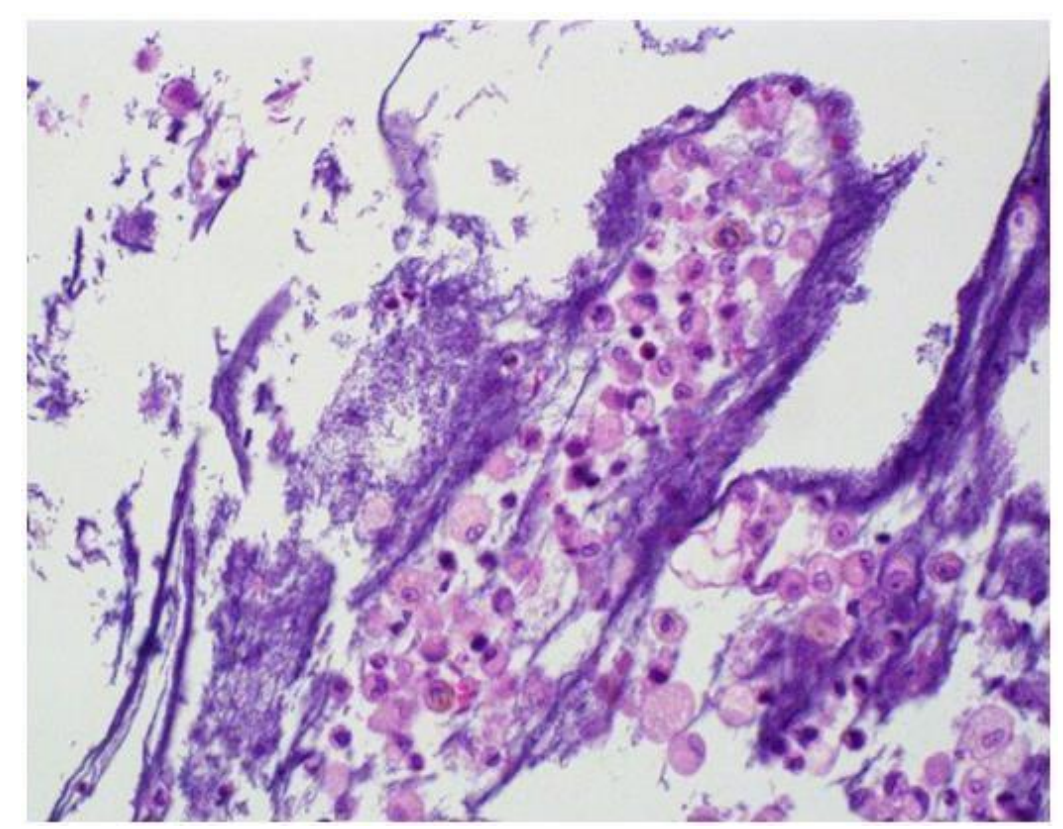

Figure. 3: Bronchoalveolar lavage showing foamy macrophages in the background of acute and chronic inflammatory cells, mucin and benign bronchial epithelial cells. Hematoxylin-eosin, original magnification x400.

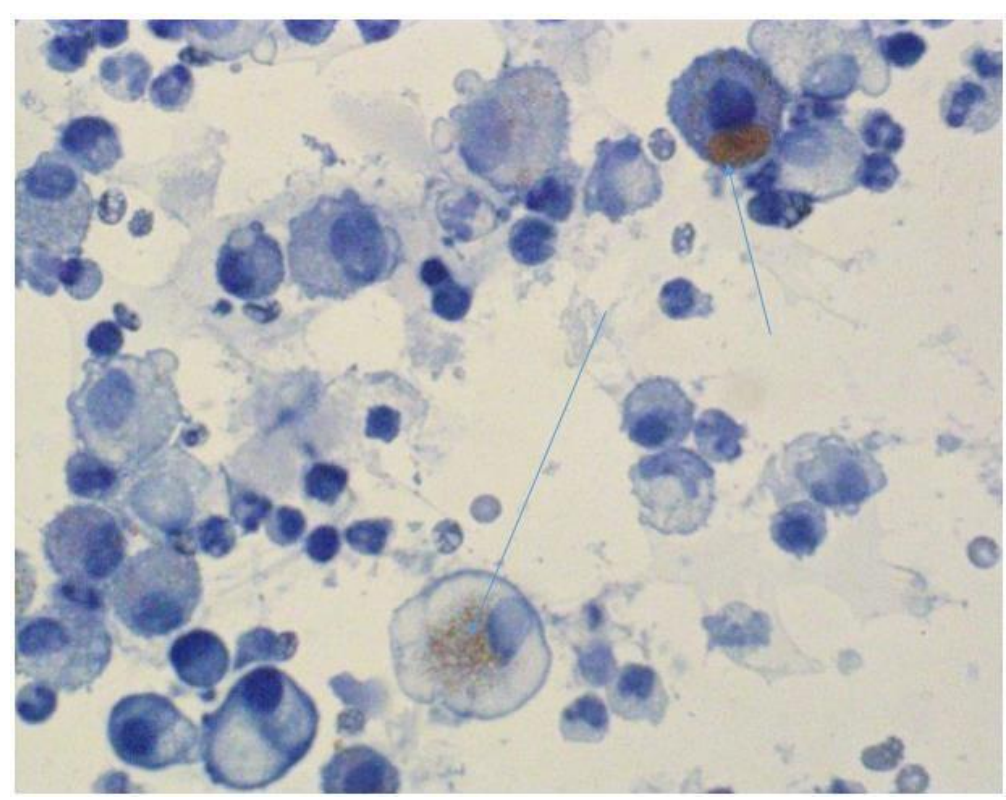

Figure. 4: Bronchoalveolar lavage fluid stained with Oil red O highlights numerous macrophages, containing lipid deposits, marked with blue arrows (lipid-laden macrophages).

\section{Discussion}

Lipoid pneumonia is a constellation of lung disease due to presence of lipids in the alveoli and is a chronic foreign body reaction to fat. It can be classified into two groups depending on an exogenous versus endogenous source of lipid or oil and host tissue reactions to the inhaled substances according to their chemical characteristics. The clinical presentation is variable ranging from subtle respiratory symptoms like dyspnea and cough to severe symptoms with life-threatening respiratory failure [3-6]. Therefore, making a diagnosis of exogenous lipoid pneumonia requires a good clinical history and high degree of clinical suspicion. Imaging findings indicating VAPl include interlobular septal thickening, diffuse infiltrates with a range of "ground glass" opacities, and nodular or "treein-bud" apical surfaces [7-9]. Cytology examination of sputum or BAL specimen showing the presence of lipid-laden macrophages is also consistent with diagnosis of PAVI; however, high lipid-laden macrophages and high lipid-laden alveolar macrophage index (LLAMI) are not specific findings and can be found in various lung diseases [10], correlation with clinical suspicion and radiologic finding is helpful.

So, the addition of foamy macrophages, extracellular oily droplets, and macrophage with large cytoplasmic vacuoles contrasting to small vacuoles in the endogenous forms is a more specific diagnosis of exogenous lipoid pneumonia [11] which may be associated with inflammatory cells like foreign body reaction with a proliferative fibrosis and macrophages with black pigmentation [12]. 
The disease outbreak is evolving rapidly. There appears to be some difference of opinion on whether VAPI is best characterized as exogenous lipoid pneumonia or chemical pneumonitis. However, the likely diagnostic path and treatment (trial and failure of albuterol and antibiotics, treatment with steroids, respiratory support and antibiotics to suppress secondary infections) remain the same. This case, with typical symptoms, imaging findings and lipid-laden macrophages on lung cytology, confers the need of early suspicion and appropriate intervention with respiratory support.

\section{Conclusion:}

Vaping associated pulmonary injury (VAPI) was established.

\section{References}

1. Centers for Disease Control and Prevention, "Outbreak of Lung Injury Associated with E-Cigarette Use, or Vaping," January 2018.

2. L. F. Chun, F. Moazed, C. S. Calfee, M. A. Matthay, and J. E. Gotts. (2017). "Pulmonary toxicity of e-cigarettes," American Journal of Physiology. Lung Cellular and Molecular Physiology, vol. 313, no. 2, pp. L193-L206.

3. K. Moore, H. Young II, and M. F. Ryan. (2015). "Bilateral pneumonia and pleural effusions subsequent to electronic cigarette use," Open Journal of Emergency Medicine, vol. 3, no. 3, pp. 18-22.

4. S. M. Frossard, P. M. Volansky, and A. S. Endara-Bravo, "A40 A HARD DAY'S NIGHT: DRUG INDUCED LUNG DISEASE: acute uvulitis secondary to electronic cigarette use," American Journal of Respiratory and Critical Care Medicine, vol. 191, p. 1.

5. J. Kaslow, R. F. Brown, and M. Fazili. (2015). "Cookies and cream lung: hypersensitivity pneumonitis leading to acute respiratory distress syndrome after electronic cigarette use," in C83. PEDIATRIC CLINICAL CHEST ROUNDS, Dallas, Texas, 2019, American Thoracic Society.

6. N. Poponea, E. Shehada, and N. Freeman, "The dark side of vaping; acute dyspnea and granulomatous lung disease associated with electronic cigarettes," in B51. CIGARETTES, E-CIGARETTES, AND HOOKAHS, San Diego, CA, USA, 2018, American Thoracic Society.

7. J. Sturek and N. Malik. (2017). "Acute hypoxic respiratory failure with crazy paving associated with electronic cigarette use," Chest, vol. 152, no. 4, p. A746,

8. K. Davidson, A. Brancato, P. Heetderks et al. (2019). "Outbreak of electronic-cigarette-associated acute lipoid pneumonia - North Carolina, July-August 2019," MWR. Morbidity and Mortality Weekly Report, vol. 68, no. 36, pp. 784-786.

9. J. E. Layden, I. Ghinai, I. Pray et al., (2020.). "Pulmonary illness related to e-cigarette use in Illinois and WisconsinFinal report," New England Journal of Medicine, vol. 382, no. 10, pp. 903-916,

10. S. Sung, H. D. Tazelaar, J. P. Crapanzano, A. Nassar, and A. Saqi. (2018). "Adult exogenous lipoid pneumonia: a rare and underrecognized entity in cytology - a case series," Cytojournal, vol. 15, no. 17, p. 17,

11. G. Rossi, A. Cavazza, P. Spagnolo et al. (2017). "The role of macrophages in interstitial lung diseases," European Respiratory Review, vol. 26, no. 145, p. 170009.

12. Z. Sheikh, P. J. Brooks, O. Barzilay, N. Fine, and M. Glogaue. (2015). "Macrophages, foreign body giant cells and their response to implantable biomaterials," Materials, vol. 8, no. 9, pp. 5671-5701,

13. Gay et al., "Vaping-Induced Lung Injury: A Case of Lipoid Pneumonia Associated with E-Cigarettes Containing Cannabis."
This work is licensed under Creative Commons Attribution 4.0 License

To Submit Your Article Click Here: Submit Article

DOI: $10.31579 / 2640-1053 / 069$
Ready to submit your research? Choose Auctores and benefit from:

*ast, convenient online submission
rigorous peer review by experienced research in your field
rapid publication on acceptance
authors retain copyrights
* unique DOI for all articles
immediate, unrestricted online access

At Auctores, research is always in progress.

Learn more www.auctoresonline.org/journals/cancer-research-andcellular-therapeutics 